apparently out of the running for political reasons, the choice of site seems to be settling down to either Hawaii or Madeira, the Atlantic Island belonging to Portugal. Professor Merle Walker of Lick Observatory, California is acting as a cosultant for the SRC during the selection process.

The decision between the two sites seems to be finely balanced. Seeing conditions are generally accepted as better on Hawaii, but by how much better is uncertain, and with the cost of an observatory on Hawaii being higher than Madeira it may yet turn out that, photon for photon, Maderia gives better value.

In the past the Science Research Council has had a reputation for keeping its ideas to itself until much too late in the day. The holding of this special meeting was therefore held to be a step in the right direction, even though it was noted that in the case of the reorganisation of the committee structure the decision had already been taken. Some participants, notably Professor Tom Kaiser (University of Sheffeld) wanted even more disclosure of the way the SRC goes about its business and Professor Martin Rees suggested that there be a series of smaller follow-up meetings to discuss particular aspects of the SRC programme.

\section{Water storage in the Wash}

\section{Eleanor Lawrence}

Since 1965 the Water Resources Board has been investigating the possibility of freshwater storage in the Wash estuary on the east coast of England. The board has recently published the interim report on the feasibility study for a proposed scheme costing $£ 140$ million, which, if implemented, will eventually provide a major new source of water for the heavily populated south-east corner of England.

A desk study completed in 1970 decided that at present a full barrage enclosing the Wash was technically impossible but authorised a practical study of the first stage of a scheme in which freshwater from the rivers Great Ouse, Nene, Welland and Witham, which flow into the Wash, would be pumped into a system of three or four artificial reservoirs built just offshore. This feasibility study, which includes an ccological survey and the construction of trial embankments, is expected to cost $£ 2.6$. million over about six years.

The area has now been completely mapped by aerial, hydrographic and land surveys. And three sets of models are under construction at the Hydraulies Research Station at Wallingford to study conditions likely to arise from building structures in the Wash and taking water from the inflowing rivers. Geological and geophysical surveys are now complete and have not revealed any major problems.

A trial inshore bank (the bank bounding the landward side of the reservoir) was successfully completed in 1972 and showed that it would be possible to construct the banks using hydraulic fill piped from the existing foreshore sediments. This bank was built entirely from the land and it was intended to construct a trial offshore bank during 1973. In the event no suitable tender was received and so construction was postponed. In view of the present financial position, however, this proposal is being completely re-examined by the government and may be cancelled, especially in view of the board's recommendation that the Wash scheme need not be considered for development until the late 1990s.

Apart from this, the other major outstanding item is the programme of hydraulic model tests. This should be completed by 1975 , says the board, and it should then be possible to pronounce on the feasibility of the first stage of the scheme, a reservoir covering 1,700 acres near the mouth of the Great Ouse.

Ecological surveys coordinated by the Natural Environment Research Council have been continuing since 1971. The Wash covers 232 square miles and contains some of the finest salt marsh and mud flat habitat in Britain. The Ouse Washes which are most likely to be affected by the development have been designated by the Nature Conservancy Council as of grade I scientific interest and are included in a register prepared by the International Union for the Conservation of Nature as being of outstanding significance.

The Wash itself is one of the most important breeding and feeding grounds in Britain of the Common Seal which, despite its name, is not so common now. As their main feeding grounds are in the outer Wash, seals are not likely to be affected by development, at least in its initial stages, unless salinity changes affect the type and abundance of food species.

The surrounding mud flats are a particularly important feeding ground for overwintering waders and wildfowl. Monthly counts suggest that the number of waders centred on the area can reach 300,000 . One of the four proposed sites for the first reservoir, Bulldog Sands to the east of the mouth of the Great Ouse, is one of the largest fceding grounds for the wading birds whereas another, on the west of the river mouth would be less acceptable to the shellfish industry, which produces about $£ 250,000$ worth of various shellfish from the Wash each year.

Final conclusions on the feasibility and siting of the reservoirs must await the results of the hydraulic model tests, final costings and the possible construction of the offshore bank. The report promises that ecological considerations will be taken into account and the Nature Conservancy Council plans to publish a separate report on overall conservation when the final results of the engineering studies are known.

\section{Physics \\ for physicists}

John Hall

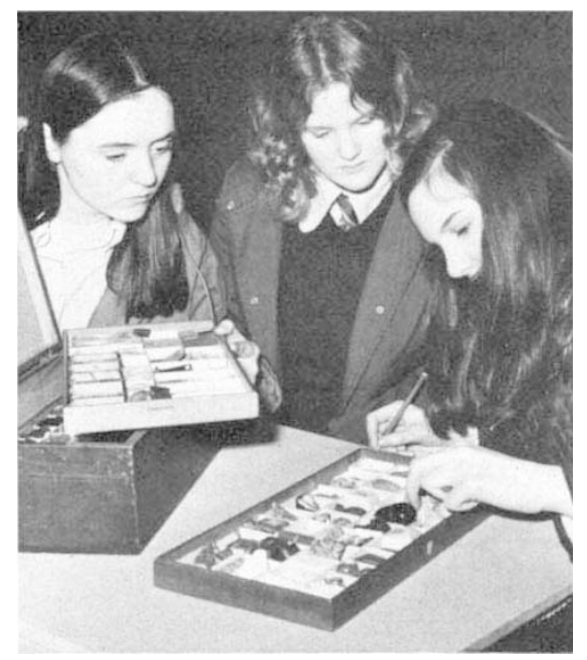

Professor Frederick Guthrie founded the Physical Society in 1874 "for showing new physical facts and new means for showing old ones, for making known new home and foreign discoveries", and one of his regular teaching aids was a compartmentalised box containing specimens of the actual insects, minerals or materials which were the subjects of his lessons. The point was that any number of descriptive talks on, say, cotton spinning, fell short of the mark if a pupil simply had no clue about the appearance, the textures, indced the nature of raw cotton. These object boxes (origin of the term 'an object lesson') are among the early exhibits in a display of physics memorabilia forming the exhibition "Phonographs to Holographs" at the Science Museum, South Kensington, in honour of the Physical Society's centenary. (Incidentally, one of the historic object boxes pictured contains, under the heading "buttcrflics", a creature which bears a .rcmarkable resemblance to a Cinnibar moth; but the spirit of the thing was clearly progressive.)

The exhibition runs to an engaging range of Victorian laboratory machines, resplendent in brass and mahogany, and 